\title{
Creep Strain Behavior in Transient Region and Minimum Creep Rate of Tempered Martensitic 9\%Cr Steel
}

\author{
Fujio Abe \\ National Institute for Materials Science \\ 1-2-1 Sengen, Tsukuba 305, Japan \\ email, ABE.Fujio@nims.go.jp
}

\begin{abstract}
Keywords: Creep rate, transient creep, $9 \mathrm{Cr}$ steel, martensite, $\mathrm{M}_{23} \mathrm{C}_{6}$ carbide, $\mathrm{MX}$ carbonitride, $\mathrm{Fe}_{2} \mathrm{~W}$ Laves phase, boron, dislocation
\end{abstract}

\begin{abstract}
The effect of fine precipitates, excess dislocations and sub-boundary hardening on creep strain behavior in the transient region has been investigated for tempered martensitic $9 \% \mathrm{Cr}$ steel at 600 and $650^{\circ} \mathrm{C}$. The fine precipitates that form during tempering or during creep decrease the creep rate in the transient region, while excess dislocations produced by cold rolling promote the recovery of dislocations during creep, resulting in higher creep rates. The sub-boundary hardening is enhanced by fine precipitates along lath and block boundaries, which retards the onset of acceleration creep. The movement and annihilation process of dislocations in the transient region is controlled by not only the movement of dislocations in the matrix but also the absorption of dislocations at boundaries. The minimum creep rate is basically determined by the time to minimum creep rate.
\end{abstract}

\section{Introduction}

Usually the creep rupture time of heat resistant steels is inversely proportional to a minimum creep rate. This is known as Monkman-Grant relationship. Therefore, the minimum creep rate should be reduced for the improvement of creep life. The minimum creep rate depends on creep strain behavior in a primary or transient creep region, which is correlated with creep strengthening mechanisms. The basic mechanisms in which creep resistant steels can be strengthened are solute hardening, precipitation or dispersion hardening, dislocation hardening and boundary or sub-boundary hardening [1]. Therefore, the appropriateness of different representation of the creep and creep rate curves depending on specific mechanisms. The decrease in creep rate by the precipitation of $\mathrm{M}_{23} \mathrm{C}_{6}$ carbides in a $10 \mathrm{Cr}-30 \mathrm{Mn}$ austenitic steel is analyzed based on the Johnson-Mehl equation for diffusion-controlled growth of precipitates from supersaturated solid solution [2].

The purpose of the present research is to investigate the effect of fine precipitates and excess dislocations on creep strain behavior in the transient region and also to make clear the role of sub-boundary hardening for tempered martensitic $9 \% \mathrm{Cr}$ steel at 600 and $650^{\circ} \mathrm{C}$.

\section{Experimental procedure}

Tempered martensitic $9 \mathrm{Cr}-(0,1,2,4) \mathrm{W}$ and $9 \mathrm{Cr}-1 \mathrm{~W}-0.2 \mathrm{~V}-0.1 \mathrm{Ta}$ (mass \%) steels were used to examine the effect of fine precipitation of $\mathrm{MC}$ carbides, where $\mathrm{M}$ denotes vanadium and tantalum, and $\mathrm{Fe}_{2} \mathrm{~W}$ Laves phase on creep strain behavior in the transient region. The carbon concentration was about $0.1 \%$ in these steels, but nitrogen was not added to avoid the precipitation of MX nitrides for simplicity. In order to examine the effect of excess dislocations, the $9 \mathrm{Cr}-1 \mathrm{~W}$ steel was cold rolled by 20 and $40 \%$ at room temperature after tempering. $9 \mathrm{Cr}-3 \mathrm{~W}-3 \mathrm{Co}-0.2 \mathrm{~V}-0.05 \mathrm{Nb}$ steels with different boron, carbon and nitrogen were also used to examine the role of sub-boundary hardening. The details of preparation of the steels are described elsewhere [3-8].

Creep test was carried out at 600 and $650^{\circ} \mathrm{C}$ for up to about $8 \times 10^{4} \mathrm{~h}$ in maximum, using specimens of $10 \mathrm{~mm}$ gauge diameter and $50 \mathrm{~mm}$ gauge length. The longitudinal cross section of the specimens was observed mainly by TEM. 


\section{Experimental results and discussion}

\section{(1) Effect of fine precipitates and excess dislocations on creep strain behavior}

Figure 1 (a) shows the creep rate versus time curves of $9 \mathrm{Cr}-(0,1,2,4) \mathrm{W}$ and $9 \mathrm{Cr}-1 \mathrm{~W}-0.2 \mathrm{~V}-0.1 \mathrm{Ta}$ steels at $650^{\circ} \mathrm{C}$ and $78 \mathrm{MPa}$. The creep rate curves consist of the primary or transient creep region, where the creep rate decreases with time, and of the tertiary or acceleration creep region, where the creep rate increases with time after reaching a minimum creep rate. There is substantially no steady-state region, where the creep rate is constant. Many researchers have shown for engineering heat resistant steels that there is an ever evolving microstructure and the change in creep rate reflects coupled elementary processes, such as change in dislocation density, change in precipitate volume fraction and size and so on [3,9-11]. These results suggest that in heat resistant steels there is no dynamic microstructural equilibrium during creep.

Only $\mathrm{M}_{23} \mathrm{C}_{6}$ carbides precipitated in the $9 \mathrm{Cr}-1 \mathrm{~W}$ steel during tempering, while both $\mathrm{M}_{23} \mathrm{C}_{6}$ and $\mathrm{MC}$ carbides precipitated in the $9 \mathrm{Cr}-1 \mathrm{~W}-0.2 \mathrm{~V}-0.1 \mathrm{Ta}$ steel [4]. In Fig.1(a), the creep rate of the $9 \mathrm{Cr}-1 \mathrm{~W}-0.2 \mathrm{~V}-0.1 \mathrm{Ta}$ steel is much lower than that of the $9 \mathrm{Cr}-1 \mathrm{~W}$ steel from the initial stage of creep. This results from the precipitation strengthening by fine $\mathrm{MC}$ carbides that form during tempering. The transient creep region of the $9 \mathrm{Cr}-1 \mathrm{~W}-0.2 \mathrm{~V}-0.1$ Ta steel continues for a longer time than in the $9 \mathrm{Cr}-1 \mathrm{~W}$ steel, resulting in a lower minimum creep rate. This suggests that fine $\mathrm{MC}$ carbides are effective for the retardation of the onset of the acceleration creep. The precipitation of $\mathrm{Fe}_{2} \mathrm{~W}$ Laves phase occurred from the supersaturated solid solution in the high-W steels, such as $9 \mathrm{Cr}-2 \mathrm{~W}$ and 9Cr-4W steels, during creep at 600 to $650^{\circ} \mathrm{C}$ [7]. In the $9 \mathrm{Cr}-2 \mathrm{~W}$ and $9 \mathrm{Cr}-4 \mathrm{~W}$ steels, the decrease in creep rate with time becomes more significant at long times above about $10 \mathrm{~h}$ in the transient region, deviating from the extrapolated lines from the short-time conditions shown by the dotted lines. It should be noted that the fine precipitation of $\mathrm{Fe}_{2} \mathrm{~W}$ Laves phase effectively decreases the creep rate in the transient region, but the large coarsening rate of $\mathrm{Fe}_{2} \mathrm{~W}$ Laves phase promotes the acceleration of creep rate after reaching a minimum creep rate.

Figure 1(b) shows the effect of cold rolling on the creep rate versus time curves of $9 \mathrm{Cr}-1 \mathrm{~W}$ steel at $600^{\circ} \mathrm{C}$ and $78 \mathrm{MPa}$. The creep rate is substantially the same in the initial stage of creep among the three different treatments. However, the less pronounced decrease in creep rate with time and the shift to shorter times of the onset of acceleration creep result in much higher minimum creep rate with increasing cold rolling level. Cold rolling enhances softening during creep by promoting the recovery of excess dislocations at elevated temperature [5], although the dislocation hardening is an important strengthening way in steel at ambient temperature.
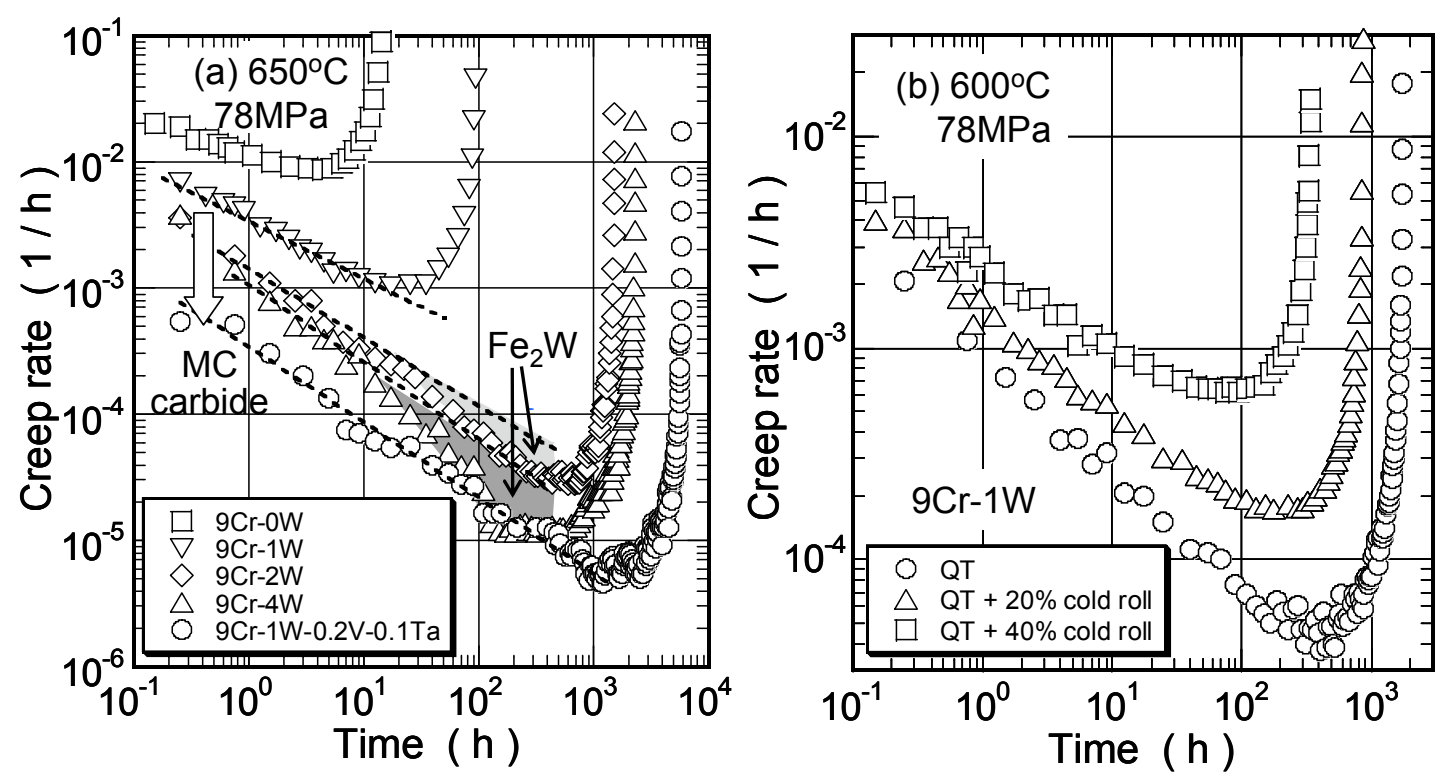

Fig.1 Creep rate versus time curves of the steels. 


\section{(2) Effect of Sub-boundary hardening on creep strain behavior}

The effect of distributions of $\mathrm{M}_{23} \mathrm{C}_{6}$ carbides and nano size $\mathrm{MX}$ nitrides along boundaries on creep strain behavior was examined using $9 \mathrm{Cr}-3 \mathrm{~W}-3 \mathrm{Co}-0.2 \mathrm{~V}-0.05 \mathrm{Nb}-0.05 \mathrm{~N}$ (mass \%) steel with different carbon concentrations of 0.002 and $0.078 \%[6,12]$. The carbon concentration of $0.078 \%$ is similar to that in conventional $9 \mathrm{Cr}$ steels such as $\mathrm{P} 92$ and $\mathrm{P} 91$. A large number of fine $\mathrm{MX}$ nitrides rich in $\mathrm{V}$ and $\mathrm{Nb}$ having a size of less than $10 \mathrm{~nm}$ but no $\mathrm{M}_{23} \mathrm{C}_{6}$ carbide are distributed along boundaries such as PAGBs and the lath, block and packet boundaries of the steel with $0.002 \% \mathrm{C}$ after tempering. This is considerably different from the microstructure of the steel with $0.078 \% \mathrm{C}$, where large particles of $\mathrm{M}_{23} \mathrm{C}_{6}$ carbides of 100 to $300 \mathrm{~nm}$ size are distributed along the PAGBs together with fine particles of MX carbonitrides. In Fig.2(a), the creep rates in the initial stage are lower in the steel with $0.002 \%$ carbon than in the steel with $0.078 \%$ carbon. The decrease in creep rate with time in the transient creep region, corresponding to the slope of the creep rate curves, is substantially the same for the two steels. The lower initial creep rate in the steel with $0.002 \%$ carbon than that in the steel with $0.078 \%$ carbon results from greater precipitation strengthening after tempering. However, the difference in the initial creep rate between the two steels is only slight, 1/3 order of magnitude, which is much smaller than the difference in the minimum creep rate between the two steels. On the other hand, the onset of acceleration creep is retarded to a later time in the steel with $0.002 \%$ carbon, which decreases the minimum creep rate.

The effect of boron on creep deformation behavior is shown in Fig. 2(b) [8]. The initial creep rates are approximately the same among the steels containing different boron contents, except for the steel with 139 ppm boron, which exhibits a slightly lower creep rate. This is due to the slightly higher nitrogen content in the steel with $139 \mathrm{ppm}$ boron. The onset of acceleration creep is retarded and the transient creep region continues for a longer time with increasing boron content. The longer duration of the transient creep region results in a lower minimum creep rate. The addition of boron does not decrease the creep rate in the transient region, which is different from the effect of dispersed nano size MX carbonitrides as shown in Fig.1(a) and Fig.2(a), but it significantly decreases the minimum creep rate by retarding the onset of acceleration creep.

As nitrogen was not added in the steel with boron, only $\mathrm{M}_{23} \mathrm{C}_{6}$ carbides are distributed along lath, block and packet boundaries and also along PAGBs after tempering but there are substantially no MX carbonitride. The fine distribution of $\mathrm{M}_{23} \mathrm{C}_{6}$ carbides along PAGBs is still maintained in the steel with $139 \mathrm{ppm}$ boron during exposure at $650^{\circ} \mathrm{C}$ [8]. In the base steel without boron, the fine distribution of $\mathrm{M}_{23} \mathrm{C}_{6}$ carbides is observed after tempering but extensive coarsening takes place in the vicinity of PAGBs during exposure at the elevated temperature. This indicates that the addition of boron reduces the rate of Ostwald ripening of $\mathrm{M}_{23} \mathrm{C}_{6}$ carbides in the vicinity of PAGBs during creep.
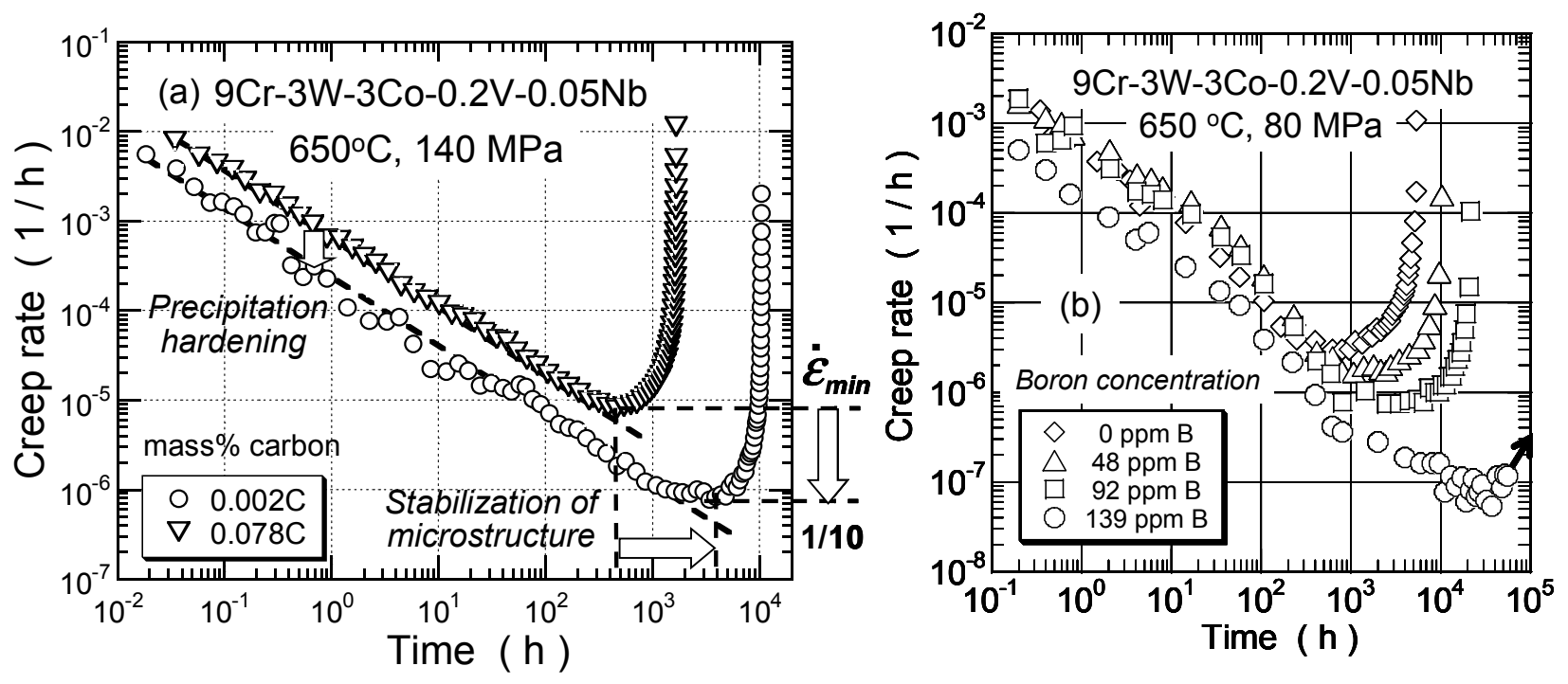

Fig. 2 Creep rate versus time curves of the steels. 


\section{(2) Dislocation movement in transient region}

We have revealed that for tempered martensitic $9 \mathrm{Cr}$ steel, transient creep is basically a consequence of the movement and annihilation of high-density dislocations produced by martensitic transformation during cooling after normalizing, and that the acceleration creep is a consequence of the gradual loss of creep strength due to the microstructure evolution [3]. We have also suggested that the migration of lath or block boundaries, causing the coarsening of the laths or blocks, is closely correlated with the onset of acceleration creep.

Schematic illustrations of dislocation movement in the model steels in Figs. 1 and 2 during transient creep are shown in Fig.3. The fine MC carbides in the matrix causes lower movement of dislocations in the matrix, resulting in lower creep rate, Fig. 1(a). The distribution of fine precipitates along lath, block and prior austenite grain boundaries are effective for the stabilization of boundaries and for the retardation of the onset of the acceleration creep. The similar effect can be expected also for the fine precipitates of $\mathrm{Fe}_{2} \mathrm{~W}$ Laves phase, Fig. 1(a). Excess dislocations produced by cold rolling causes a large driving force for dislocation recovery during creep, resulting in higher creep rates, Fig. 1(b).

Whereas the density of precipitates along boundaries is much higher in the steel with $0.002 \%$ carbon than in the steel with $0.078 \%$ carbon, Fig. 2(a), the density of MX carbonitrides in the matrix within the laths is lower in the steel with $0.002 \%$ carbon than in the steel with $0.078 \%$ carbon: $5.5 \times$ $10^{13}$ and $7.5 \times 10^{13} / \mathrm{m}^{2}$ for the steels with 0.002 and $0.078 \%$ carbon, respectively [12]. This is because the amount of MX carbonitrides along the boundaries is much larger in the steel with $0.002 \%$ carbon than in the steel with $0.078 \%$ carbon, since there are no $\mathrm{M}_{23} \mathrm{C}_{6}$ carbides in the steel with $0.002 \%$ carbon. On the other hand, most of the MX carbonitrides in the steel with $0.078 \%$ carbon are distributed in the matrix and only a small amount of MX carbonitrides are distributed along the boundaries together with a large amount of $\mathrm{M}_{23} \mathrm{C}_{6}$ carbides. The fine $\mathrm{MX}$ carbonitrides in the matrix act as obstacles to dislocation movement to lath and block boundaries, which reduces the number of dislocation annihilations and decreases the creep rate, as illustrated in Figs. 3(a) and 3(b). At lath and block boundaries, the climbing and redistribution of dislocations in the boundary wall are prohibited when dense distributions of $\mathrm{MX}$ and $\mathrm{M}_{23} \mathrm{C}_{6}$ in the boundary wall act as obstacles, which decreases the efficiency of dislocation absorption at the boundaries. This also reduces the number of dislocation annihilations and decreases the creep rate. On the basis of the results described above, the creep rate in the transient region is given by

$$
\dot{\varepsilon}=\rho_{f} v_{g} b \eta
$$

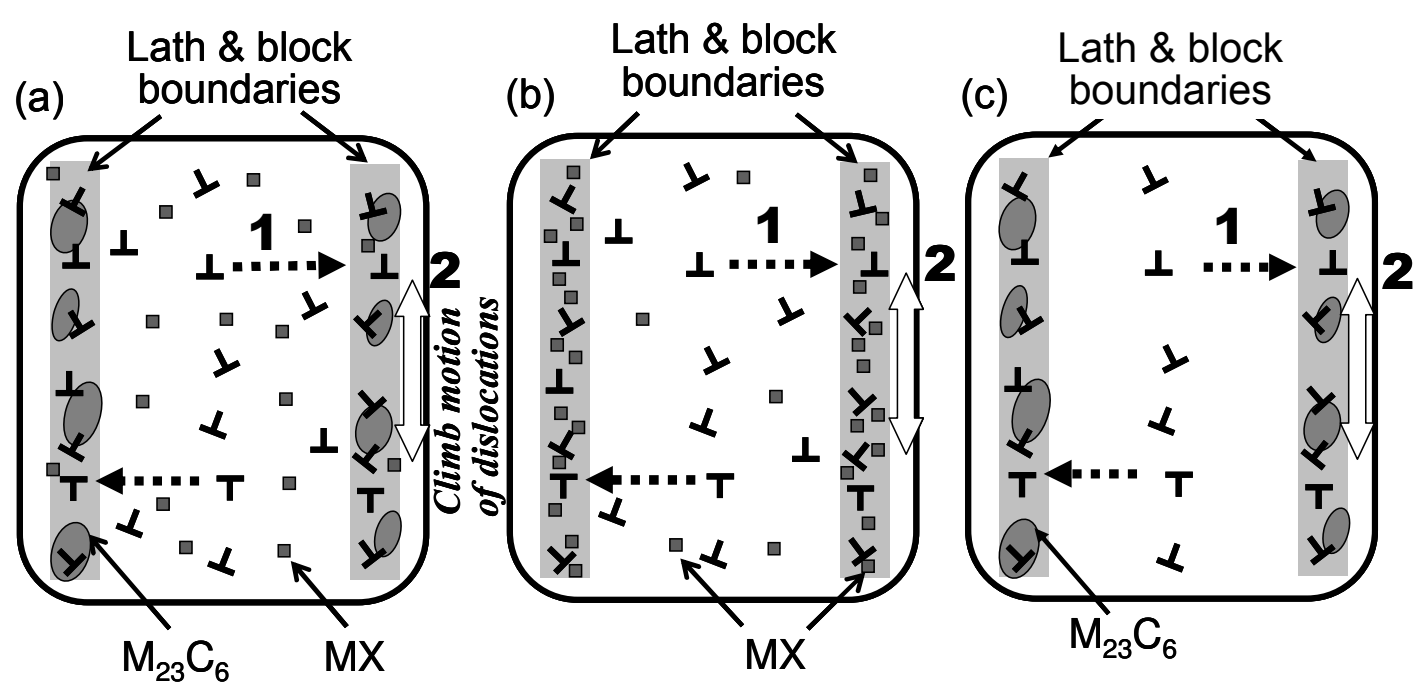

Fig.3 Schematics of dislocation movement in lath and block microstructure of $9 \mathrm{Cr}$ steel. (a) $0.078 \% \mathrm{C}-0.05 \% \mathrm{~N}$, (b) $0.002 \% \mathrm{C}-0.05 \% \mathrm{~N}$ and (c) $0.078 \% \mathrm{C}-0 \mathrm{~N}-(0-0.014) \%$ boron 
where $\rho_{f}$ is the free dislocation density in the matrix within the laths, $v_{g}$ is the velocity of free dislocations in the matrix, $b$ is the magnitude of the Burgers vector and $\eta$ is the efficiency of dislocation absorption at boundaries. The present results of lower creep rates in the steel with $0.002 \%$ carbon than in the steel with $0.078 \%$ carbon in the transient region suggest that the lower $\eta$ in the steel with $0.002 \%$ carbon due to fine distribution of MX carbonitrides along the boundaries is the main factor causing the lower creep rate in the transient region rather than precipitation strengthening due to fine MX carbonitrides in the matrix. The agglomeration and coarsening of precipitates at the boundaries during transient creep promote the climbing and redistribution of dislocations in the boundary walls, resulting in an increase in the efficiency of dislocation absorption at the boundaries. The absorption of dislocations at the boundaries accelerates further agglomeration and coarsening of the precipitates and also promotes the climbing and redistribution of dislocations in the boundary walls. These chain reactions increase the migration of lath or block boundaries, promoting the onset of acceleration creep. The observed significant decrease in the minimum creep rate by reducing the carbon concentration is explained mainly by the retardation of the onset of acceleration creep, resulting from the stabilization of the lath-block microstructure during creep. The present results suggest that sub-boundary hardening enhanced by fine distributions of precipitates along the lath and block boundaries is the main strengthening mechanism in the present $9 \mathrm{Cr}$ steel.

The velocity of free dislocations in the matrix and the efficiency of dislocation absorption at boundaries are considered to be the same among the steels containing different boron concentrations in the initial stage of creep, Fig.3(c), because the distribution of $\mathrm{M}_{23} \mathrm{C}_{6}$ carbides along boundaries is substantially the same for the steels after tempering as described above. This causes the same creep rates for the steels with boron in the transient region. However, the fact that boron reduces the coarsening rate of $\mathrm{M}_{23} \mathrm{C}_{6}$ carbides near PAGBs suggests that the onset of acceleration creep is retarded, which results in lower minimum creep rate, Fig.2(b). The sub-boundary hardening enhanced by $\mathrm{M}_{23} \mathrm{C}_{6}$ carbides along lath and block boundaries is a main strengthening mechanism in the present steel and the addition of boron enhances the sub-boundary hardening near PAGBs at long times through stabilization of fine distributions of $\mathrm{M}_{23} \mathrm{C}_{6}$ carbides.

\section{(4) Controlling factors for minimum creep rate}

Figure 4(a) shows the stress dependence of the minimum creep rate $\dot{\varepsilon}_{\text {min }}$ for the steels with different boron at $650{ }^{\circ} \mathrm{C}$ in Fig. 2(b). The stress exponent $n$ of the minimum creep rate $\left(\dot{\varepsilon}_{\min }=A \sigma^{n}\right)$ is evaluated to be 15-20 for the steels with and without boron at high stresses above $110 \mathrm{MPa}$. With decreasing stress below $110 \mathrm{MPa}$, the stress dependence of the minimum creep rate deviates upward and the stress exponent $n$ gradually decreases to a low value of about 3 for the 0 ppm B, 48 ppm B and
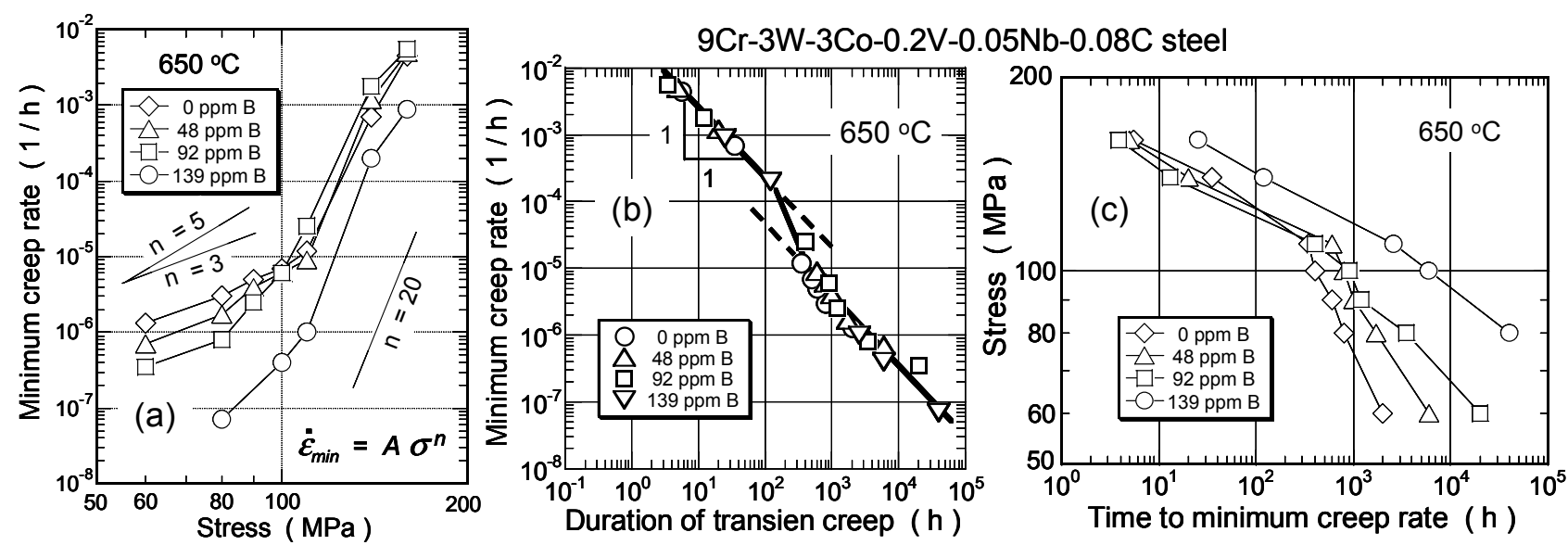

Fig.4 (a) Stress dependence of minimum creep rate, (b) minimum creep rate versus time to minimum creep rate and (c) stress versus time to minimum creep rate for the $9 \mathrm{Cr}$ steel with different boron. 
$96 \mathrm{ppm}$ B steels. The transition from the large $n$ to the small $n$ shifts to lower stresses and longer times with increasing boron content. The minimum creep rate is inversely proportional to the time to minimum creep rate, corresponding to the duration of transient creep, Fig. 4(b). The relationship between the minimum creep rate and time to minimum creep rate is described by a unique line shown in Fig.4(b), independent of boron content. This suggests that the creep deformation mechanisms in the transient creep region are the same among the steels containing different boron contents. A sharp drop in minimum creep rate from about 100 to $400 \mathrm{~h}$ is caused by the precipitation of a fine $\mathrm{Fe}_{2} \mathrm{~W}$ Laves phase. The time to minimum creep rate depends on boron content as well as stress level as shown in Fig. 4(c). The addition of boron effectively retards the onset of acceleration creep and extends the transient creep to longer times at low stresses below $110 \mathrm{MPa}$, which results in lower minimum creep rate. The other model steels shown in Figs. 1 and 2 show that the minimum creep rate is basically determined by the time to minimum creep rate.

\section{Summary}

(1) The fine MC carbides that form during tempering decrease the creep rate from the initial stage of creep and retard the onset of acceleration creep. The precipitation of $\mathrm{Fe}_{2} \mathrm{~W}$ Laves phase takes place during creep in the high-W steels such as $9 \mathrm{Cr}-2 \mathrm{~W}$ and $9 \mathrm{Cr}-4 \mathrm{~W}$ at 600 and $650^{\circ} \mathrm{C}$, resulting in that the decrease in creep rate with time becomes more significant in the transient region. Excess dislocations produced by cold rolling promote the recovery of dislocations during creep, resulting in higher creep rates in the transient region.

(2) The sub-boundary hardening is enhanced by fine distributions of precipitates along lath and block boundaries, which retards the onset of acceleration creep and hence decreases minimum creep rate. The sub-boundary hardening is shown to be the most important strengthening mechanism in creep of tempered martensitic $9 \mathrm{Cr}$ steel.

(3) The movement and annihilation process of dislocations in the transient region is controlled by not only the movement of dislocations in the matrix but also the absorption of dislocations at boundaries.

(4) The minimum creep rate is basically determined by the time to minimum creep rate. The time to minimum creep rate is correlated with the stability of martensitic microstructure during creep.

\section{Acknowledgement}

The author would like to thank all members participating with Ultra-Steel Project at NIMS. He is also grateful to members of the Creep Group at NIMS for their sincere efforts.

\section{References}

[1] F. Abe: Science and Technology of Advanced Materials, 9 (2008) 013002.

[2] F. Abe: Metall. Trans. A, 26A, (1995) 2237-2246.

[3] F. Abe, S. Nakazawa, H. Araki and T. Noda, Metall. Trans., 23A (1992) 469-477.

[4] F. Abe: Materials Science and Engineering, A319-321 (2001) 770-773.

[5] F. Abe: Metall. Mater. Trans. A, 34A (2003) 913-925.

[6] M. Taneike, F. Abe and K. Sawada: Nature, 424 (2003) 294-296.

[7] F. Abe, Metall. Mater. Trans. A, 36A (2005) 321-332.

[8] F. Abe: Intern. J. Materials Research, 99 (2008) 387-394.

[9] K. R. Williams and B. Wilshire, Mater. Sci. Eng., 28 (1977) 289-96.

[10] G. Eggeler, N. Nilsvang and B. Ilschner, Steel Research, 58 (1987) 97-103.

[11] S. Straub, M. Meier, J. Ostermann and W. Blum, VGB Kraftwerkstechnik, 73 (1993) 646-653.

[12] M. Taneike, K. Sawada and F. Abe: Metall. Mater. Trans. A, 35A (2004) 1255-1262. 